\title{
Anxiety Level of Students towards Getting a Residency and Fellowship Program: A Survey of Pharmacy Students
}

\author{
Ronald Smith ${ }^{1}$ and Bisrat Hailemeskel*2 \\ ${ }^{1}$ Senior Pharmacy Student, College of Pharmacy, Howard University, USA \\ ${ }^{2}$ Associate Professor of Pharmacy Practice \& Co-Director of International Grants, Howard University, USA
}

Received: March 30, 2018; Published: April 11, 2018

*Corresponding author: Bisrat Hailemeskel, Howard University, $23004^{\text {th }}$ Street, NW, Washington, DC, 20059, USA, Email: bhailemeskel@howard.edu

Abstract

Introduction: Studies assessing the anxiety and stress levels in students that consider residency and fellowship programs post-graduation are minimal in the literature. Evaluating student confidence on pursuing residency or fellowship may provide insight in to the level of students concerns. The goal of this study is to obtain students' opinion of their concerns of obtaining a residency or fellowship training upon graduation.

Method: The survey consisted of 6 questions that were graded on a 5-level Likert scale (strongly disagree, disagree, neutral, agree, and strongly agree) and it was administered to third-year professional pharmacy students of Howard University College of Pharmacy.

Results: Data collected showed53 students completed the survey with an 85\% response rate. Of the students, over half (55\%) expressed interest in pursuing a residency or fellowship program. Comparing their interest between a residency or a fellowship program, over half of the respondents have more interest in pursuing a residency program than a fellowship. Although seventy percent (69.7\%) of students said that they were actively searching for a residency and/or fellowship programs, about two-third of them (75.6\%) are very concerned with finding a residency or fellowship after graduation. Greater than eighty seven percent (87.5\%) of students actively think and over three-quarter of participants $(75.6 \%)$ actively discuss with classmates or colleagues about residency or fellowship during their pharmacy school careers. Close to about three-fourth (72.7\%) of students expressed flexibility in moving to any state, if they need to, to start a residency or fellowship. However, when stratified across various demographic measures such as age, gender, pharmacy related work experience, and education, it was shown that these factors do not have an impact on students' concerns.

Conclusion: Results of this study may inspire potential curriculum changes that may better prepare students for these career paths, or the development of anxiety and stress relief programs for pharmacy students.

\section{Introduction}

Pharmacy students who are interested in pursuing a more clinically oriented career upon graduation are expected to do a residency or a fellowship program. The major difference between the two programs is that the residency is clinically-focused and a fellowship is a research-focused program. Those who choose residency training have two choices. The first is to enroll in a Postgraduate year one (PGY-1) training program which offers a more generalized training by providing residents exposure to a broad range of clinical scenarios. The second choice is a Postgraduate year two (PGY-2), a program that offers a more specialized area of training. In the United States, the majority of accredited residency programs accept students through a centralized service sponsored by the American Society of Health-System Pharmacists (ASHP) [1]. This service matches an applicant (a pharmacist or graduating pharmacy student) with a residency program. After the interview process, both the applicant and the residency program rank their preferences.

Unlike a residency program, fellowship programs are less centralized and vary from institution to institution. Some fellowships accept students directly upon graduation from a college of pharmacy while others require students to complete a one-year residency program. Most pharmaceutical companies also have a fellowship program. A fellowship in industry can be 1 or 2 years and may be on-site with a drug company, associated with a university, or both. In the past few years, there is a significant interest by new graduates in pursuing these post-doctoral trainings which creates intense competition and anxiety among students. Based on ASHP statistics, about one-third applicants do not match with a residency 
program [1]. The number of students left unmatched is expected to grow as more new graduates are entering into the matching program. The lack of adequate number of residency or fellowship programs nationally and the increasing number of new graduates entering the market, create anxiety and worry among pharmacy students who dream to pursue these routes upon graduation.

In general, students in healthcare professions have higher anxiety levels compared to normative values in the general population based on the study published by Macauley $\mathrm{K}$ et al. [2]. Three-hundred and fifty-one, first and second year Doctor of Physical Therapy, Master of Science in Communication Science Disorders, and Master of Physician Assistant studies students were recruited to participate in this study. According to their study, 53\% of females and $37.5 \%$ of males have at least moderately high level of anxiety. Eighty-three percent of students have greater than normal State Anxiety and 56\% of students have higher than normal Trait Anxiety levels.

The prevalence and severity of anxiety among students becomes even more complicated with tighter post-graduate opportunities including residency, fellowship, or further specialized training. Elevated levels of anxiety may decrease students' academic performance, professionalism, and their ability to manage elements of patient care. Anxiety and the impact of anxiety have been well studied in medical and nursing students, but it has not been investigated as much in other healthcare professions programs including among pharmacy students. Therefore, the goal of this study is to identify the level of concerns and worriedness among pharmacy students towards getting residency or fellowship program upon graduation.

\section{Methods}

A 6 question survey was given to third-year professional pharmacy students at Howard University as a part of an Integrated Therapeutics course. Participation in the survey was voluntary and anonymous. The questionnaire focused on the opinions of students that were interested in pursuing a residency or fellowship postgraduation. The survey consisted of 13 questions, with 6 of the questions being based on a 5-level Likert scale (strongly disagree, disagree, neutral, agree, and strongly agree). Several questions were asked of students' demographic characteristics including their age range, gender, prior college education, pharmacy work-related experience, and home state. Survey results were inputted and analyzed using SPSS software. Descriptive statistics, multivariate analysis, and Pearson correlation tests were performed to determine the impact of demographic on the dependent variables.

\section{Results}

Of the 53 total respondents, (83\% response rate) stated they were between the ages 20-29 years. Over half of the respondents $(60.4 \%)$ were $25-29$. About ninety percent (92\%) reported having at least a bachelor's degree (Table 1). Of these, 10 percent of them reported having graduate degrees (Masters' and Ph.D.). Participants were also asked about their job experience in pharmacy-related fields. One-third said they have no pharmacy related experience while the majority of participants (66\%) said they have at least 1 year of work experience, with a maximum of 8 years. Survey participants came from 14 different states, as well as the District of Columbia (DC), with over half of the students (53.4\%) coming from the DC, Maryland and Virginia. The other states with the highest number of students reported were Georgia, Pennsylvania, and Texas. When asked if they were interested in returning to their home states upon graduation, $44.7 \%$ answered "Yes", and over a third (38.3\%) were unsure.

Table 1: Demographics of Respondents.

\begin{tabular}{|c|c|c|}
\hline Characteristic & Percentage of Users & No. Of Participants \\
\hline \multicolumn{3}{|l|}{ Gender } \\
\hline Male & 30.8 & 16 \\
\hline Female & 69.2 & 36 \\
\hline \multicolumn{3}{|l|}{ Age (in years) } \\
\hline $20-24$ & 22.6 & 12 \\
\hline $25-29$ & 60.4 & 32 \\
\hline $30-34$ & 13.2 & 7 \\
\hline $35-39$ & 3.8 & 2 \\
\hline \multicolumn{3}{|c|}{ Pharmacy Related Work Experience } \\
\hline 0 & 30.2 & 16 \\
\hline 0.5 & 173.8 & 2 \\
\hline 1 & 5.7 & 3 \\
\hline 1.5 & 1.96 & 1 \\
\hline 2 & 17 & 9 \\
\hline 3 & 11.3 & 6 \\
\hline 4 & 17 & 9 \\
\hline 5 & 5.7 & 3 \\
\hline 6 & 1.9 & 1 \\
\hline 7 & 1.9 & 1 \\
\hline 8 & 3.8 & 2 \\
\hline \multicolumn{3}{|l|}{ Education } \\
\hline Associate & 8 & 4 \\
\hline $\mathrm{BA} / \mathrm{BSc}$ & 78 & 39 \\
\hline MA/MSc & 8 & 4 \\
\hline Ph.D. & 2 & 1 \\
\hline Other & 4 & 2 \\
\hline \multicolumn{3}{|l|}{ Home State } \\
\hline $\mathrm{CA}$ & 1.9 & 1 \\
\hline DC & 5.8 & 3 \\
\hline GA & 5.8 & 3 \\
\hline KA & 1.9 & 1 \\
\hline LA & 1.9 & \\
\hline MD & 36.5 & 1 \\
\hline MI & 3.8 & 19 \\
\hline MN & 1.9 & 2 \\
\hline NC & 1.9 & 1 \\
\hline $\mathrm{NJ}$ & 1.9 & 1 \\
\hline
\end{tabular}




\begin{tabular}{|c|c|c|}
\hline NV & 1.9 & 1 \\
\hline NY & 5.8 & 1 \\
\hline OH & 1.9 & 3 \\
\hline PA & 5.8 & 1 \\
\hline SC & 3.8 & 3 \\
\hline TX & 5.8 & 2 \\
\hline VA & 11.5 & 6 \\
\hline
\end{tabular}

they were actively searching for a residency and/or fellowship programs. Close to about three-fourth (72.7\%) of students expressed flexibility in moving to any state, if they need to, to start a residency or fellowship (Table 2).Over three-quarter (75.6\%) of the study participants said they actively discuss with classmates or colleagues about residency or fellowship. Interestingly, another three-quarter $(75.7 \%)$ of students expressed concern with finding a residency or fellowship program. Comparing their interest between a residency and a fellowship program, over half of the respondents have more interest in pursuing a residency program than a fellowship. Greater than eighty seven (87.5\%) of students actively think about residency during their pharmacy school careers. interested in pursuing a residency or fellowship upon graduation (Table 2). About seventy percent (69.7\%) of students said that

Table 2: Survey Questionnaire.

\begin{tabular}{|c|c|c|c|c|c|}
\hline Survey Questionnaire & \multicolumn{2}{|l|}{ Yes } & \multicolumn{3}{|c|}{ No } \\
\hline I am interested in doing a residency or fellowship upon graduation & \multicolumn{2}{|l|}{$64.7 \%$} & \multicolumn{3}{|c|}{$33.3 \%$} \\
\hline & Strongly Disagree & Disagree & No Opinion & Agree & Strongly Agree \\
\hline I am actively searching for a residency and/or fellowship programs & $3 \%$ & $15.2 \%$ & $12.1 \%$ & $30.3 \%$ & $39.4 \%$ \\
\hline $\begin{array}{l}\text { I am flexible to move to any state, if I need to, to start a residency or } \\
\text { fellowship }\end{array}$ & $3 \%$ & $12.1 \%$ & $12.1 \%$ & $24.2 \%$ & $48.5 \%$ \\
\hline $\begin{array}{l}\text { I often think about residency or fellowship during my pharmacy } \\
\text { school career }\end{array}$ & $3.1 \%$ & $3.1 \%$ & $6.3 \%$ & $34.4 \%$ & $53.1 \%$ \\
\hline $\begin{array}{l}\text { I often discuss with classmates or colleagues about residency or } \\
\text { fellowship }\end{array}$ & $0 \%$ & $15.2 \%$ & $9.1 \%$ & $33.3 \%$ & $42.4 \%$ \\
\hline I am concerned about finding a residency or fellowship program & $3 \%$ & $6.1 \%$ & $15.2 \%$ & $30.3 \%$ & $45.5 \%$ \\
\hline I am more interested in residency than a fellowship program & $15.2 \%$ & $15.2 \%$ & $15.2 \%$ & $24.2 \%$ & $30.3 \%$ \\
\hline
\end{tabular}

\section{Discussion}

The primary goal of this study was to identify if students who are interested in pursuing residency or fellowship have anxiety and/or worry about obtaining one upon graduation. A noteworthy finding in this study was that there was a significant amount of students interested in residency and/or fellowships. Majority of them said that they often think about these opportunities during their pharmacy career. However, despite their interest, a significant amount of students are concerned about finding a residency or fellowship program. As the demand for pharmacists decreases due to an increase in the number of pharmacy graduates, students are looking for ways to make themselves more marketable in a competitive job market by pursuing additional job training or education post-graduation $[3,4]$.

Of the 2017 graduating students that participated in the ASHP match, $66 \%$ of students successfully matched to a PGY1 residency program. [1]Thematch acceptance rate could have an impact on student's anxiety about residency or fellowship but a question was not asked to assess this specific concern. A limitation of the study was a small sample size. The study only included third professional year students who were enrolled in a required Integrated Therapeutics class. Thus, the data does not represent a true cross section of pharmacy students at Howard University College of Pharmacy or colleges and schools of pharmacy across the country. A clinical assessment tool to measure depression, anxiety, and stress levels of students was not included in the questionnaire, but its inclusion in a future study may prove beneficial to providing valuable insights into students' opinions.

\section{Conclusion}

As students matriculate through pharmacy school and approach graduation, the thought of pursuing residency and fellowship can create increased anxiety and stress levels. Pharmacy schools may consider looking into ways to help students alleviate stress and anxiety, or create modifications in curriculum that may increase preparedness in students pursuing these post graduate opportunities so that they have a decreased level of stress and anxiety.

\section{References}

1. (2018) National Matching Services Inc (2018).

2. Kelly Macauley, Laura Plummer, Charlotte Bemis, Genevieve Brock, Christine Larson, et al. (2018) Prevalence and predictors of anxiety in healthcare professions students. Health Professions Education.

3. Migliore MM, Costantino RC, Campagna NA, Albers DS (2013) Educational and career goals of pharmacy students on graduation. Am J Pharm Educ 77(9): 187.

4. Bucci KK, Knapp KK, Ohri LK, PJ Brooks (1995) Factors Motivating Pharmacy Students to Pursue residency and Fellowship Training. Am J Health-Syst Pharm 52(23): 2696-2701. 
(c) (1) This work is licensed under Creative

Submission Link: https://biomedres.us/submit-manuscript.php

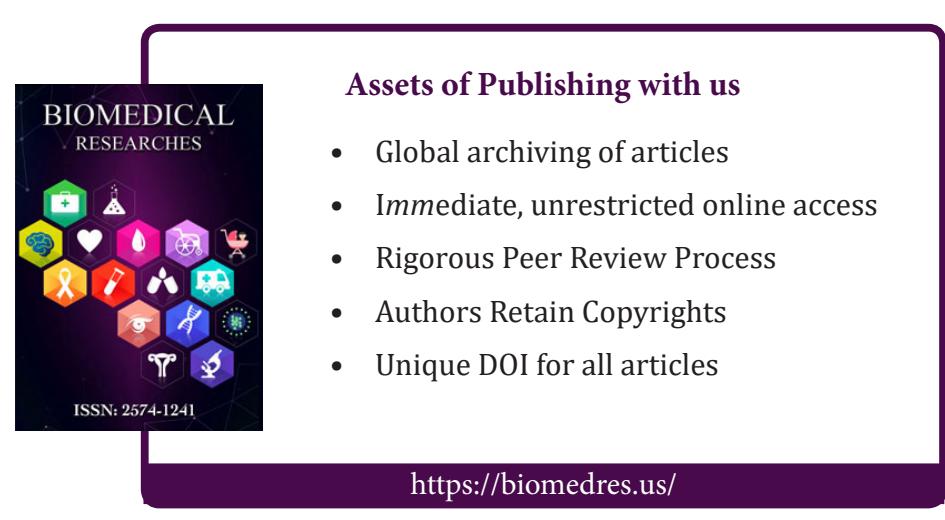

